\title{
Impaired Neural Response to Negative Prediction Errors in Cocaine Addiction
}

\author{
Muhammad A. Parvaz, ${ }^{1}$ Anna B. Konova, ${ }^{2}$ Greg H. Proudfit,${ }^{3}$ Jonathan P. Dunning, ${ }^{4}$ Pias Malaker, ${ }^{1}$ Scott J. Moeller, ${ }^{1}$ \\ Tom Maloney, ${ }^{1}$ Nelly Alia-Klein, ${ }^{1}$ and Rita Z. Goldstein ${ }^{1}$ \\ ${ }^{1}$ Department of Psychiatry and Neuroscience, Icahn School of Medicine at Mount Sinai, New York, New York 10029, ${ }^{2}$ Center for Neural Science, New York \\ University, New York, New York 10003, 32Department of Psychology, Stony Brook University, Stony Brook, New York 11970, and ${ }^{4}$ Department of \\ Psychology, Nevada State College, Henderson, Nevada 89002
}

Learning can be guided by unexpected success or failure, signaled via dopaminergic positive reward prediction error ( $+\mathrm{RPE})$ and negative reward-prediction error (-RPE) signals, respectively. Despite conflicting empirical evidence, RPE signaling is thought to be impaired in drug addiction. To resolve this outstanding question, we studied as a measure of RPE the feedback negativity (FN) that is sensitive to both reward and the violation of expectation. We examined FN in 25 healthy controls; 25 individuals with cocaine-use disorder (CUD) who tested positive for cocaine on the study day (CUD +), indicating cocaine use within the past $72 \mathrm{~h}$; and in $25 \mathrm{individuals}$ with CUD who tested negative for cocaine (CUD-). EEG was acquired while the participants performed a gambling task predicting whether they would win or lose money on each trial given three known win probabilities $(25,50$, or $75 \%)$. FN was scored for the period in each trial when the actual outcome (win or loss) was revealed. A significant interaction between prediction, outcome, and group revealed that controls showed increased FN to unpredicted compared with predicted wins (i.e., intact $+\mathrm{RPE}$ ) and decreased FN to unpredicted compared with predicted losses (i.e., intact - RPE). However, neither CUD subgroup showed FN modulation to loss (i.e., impaired - RPE), and unlike CUD + individuals, CUD - individuals also did not show FN modulation to win (i.e., impaired + RPE). Thus, using FN, the current study directly documents - RPE deficits in CUD individuals. The mechanisms underlying - RPE signaling impairments in addiction may contribute to the disadvantageous nature of excessive drug use, which can persist despite repeated unfavorable life experiences (e.g., frequent incarcerations).

Key words: addiction; cocaine; event-related potentials; feedback negativity; reward-prediction error; self-medication

\section{Introduction}

Reinforcement-learning theories posit that a reward-prediction error (RPE) signal reflects a discrepancy between a predicted and actual rewarding outcome that is used to update the expected value of the stimulus/action leading to the rewarding outcome (Schultz, 1998; Glimcher, 2011). According to both preclinical and human neuroimaging studies, these RPEs are produced by phasic dopaminergic signaling in the midbrain projecting to other regions within the mesostriatocortical network that increases in response to the delivery of an unpredicted reward [positive RPE (+RPE)] and decreases in response to either the omission of a predicted reward or delivery of negative outcome [negative RPE (-RPE); Mirenowicz and Schultz, 1994; Hollerman and Schultz, 1998; McClure et al., 2003; Liu et al., 2007;

Received July 7, 2014; revised 0ct. 28, 2014; accepted Dec. 2, 2014.

Author contributions: M.A.P., G.H.P., N.A.-K., and R.Z.G. designed research; M.A.P., A.B.K., J.P.D., P.M., and T.M. performed research; M.A.P., A.B.K., J.P.D., and S.J.M. analyzed data; M.A.P. wrote the paper.

This work was supported by grants from the National Institute on Drug Abuse (F32DA033088 to M.A.P.; R21DA034954 to R.Z.G.) and from the National Institute on Mental Health (5T32MH019524 to A.B.K.; R01MH090134 to N.A.K.).

The authors declare no competing financial interests.

Correspondence should be addressed to Rita Z. Goldstein, One Gustave Levy Place, New York, NY 10029. E-mail: rita.goldstein@mssm.edu.

DOI:10.1523/JNEUROSCI.2777-14.2015

Copyright $\odot 2015$ the authors $\quad 0270-6474 / 15 / 351872-08 \$ 15.00 / 0$
Cohen et al., 2012; Hart et al., 2014]. Consequently, these signals drive learning (Reynolds et al., 2001) that guides future behavior (Montague et al., 2004; Frank and Claus, 2006).

In the course of developing drug addiction, the pharmacologic actions of drugs of abuse enhance + RPE signal (Jones et al., 1995), facilitating pathological overlearning of drug-related cues (Di Chiara, 1998). The mechanism invokes dysregulated corticostriatal dopamine transmission (Rice and Cragg, 2004) that facilitates unrestricted habitual drug use (Everitt and Robbins, 2005) and results in gradual decline in dopaminergic functions (Koob and Le Moal, 2001), including reward prediction (Watanabe, 1996) and movement initiation (Schultz and Romo, 1992). Using associative learning and guessing/financial decision-making tasks, some studies have shown reduced RPE signals in nicotine (Rose et al., 2012), polysubstance (Tanabe et al., 2013), and stimulant (Rose et al., 2014) users, whereas others have shown intact RPE signals in alcohol (Park et al., 2010), nicotine (Chiu et al., 2008), and opioid (Gradin et al., 2014) users. Thus, whether RPE signaling is globally impaired in addiction remains an open question.

The feedback-related negativity [feedback negativity (FN), feedback-related negativity, feedback-error-related negativity, or medial-frontal negativity] component of the event-related potentials (ERPs) originates from the medial prefrontal cortex and 
Table 1. Demographics and drug use-related measures of all study participants ${ }^{a}$

\begin{tabular}{|c|c|c|c|c|}
\hline & Test & Controls & CUD+ & CUD- \\
\hline & $\left(\chi^{2}, F, t\right.$ or $\left.Z\right)$ & $(N=25)$ & $(N=25)$ & $(N=25)$ \\
\hline \multicolumn{5}{|l|}{ Demographics } \\
\hline Gender: female/male & 3.2 & $2 / 23$ & $1 / 24$ & $3 / 22$ \\
\hline Race: African-American/other ${ }^{b}$ & 9.2 & $17 / 8$ & $19 / 6$ & $18 / 7$ \\
\hline Age (years) & 2.0 & $40.8 \pm 7.3$ & $44.9 \pm 4.5$ & $42.5 \pm 7.7$ \\
\hline Education (years) & 0.6 & $13.0 \pm 3.2$ & $13.1 \pm 1.7$ & $12.2 \pm 1.5$ \\
\hline Nonverbal IQ: Wechsler Abbreviated Scale of Intelligence: Matrix Reasoning Scale & 0.3 & $9.6 \pm 3.4$ & $9.7 \pm 3.3$ & $10.1 \pm 2.9$ \\
\hline Depression: Beck Depression Inventory II & 2.8 & $3.4 \pm 4.7$ & $5.4 \pm 5.2$ & $4.8 \pm 4.0$ \\
\hline Socioeconomic status: Hollingshead Index & 0.1 & $33.2 \pm 12.6$ & $33.4 \pm 11.1$ & $32.7 \pm 11.2$ \\
\hline \multicolumn{5}{|l|}{ Drug use } \\
\hline Cigarette smokers (current smokers/past smokers/nonsmokers) & $23.2^{*}$ & $5 / 3 / 17$ & $16 / 3 / 6$ & $16 / 5 / 4$ \\
\hline Daily cigarettes (current smokers: $N=5 / 16 / 16$ ) & 0.6 & $1.4 \pm 3.5$ & $6.3 \pm 6.8$ & $5.0 \pm 4.6$ \\
\hline Age of onset of cocaine (years) & 0.4 & - & $24.9 \pm 5.8$ & $25.8 \pm 7.0$ \\
\hline Duration of use of cocaine (years) & 0.2 & - & $15.8 \pm 5.8$ & $15.5 \pm 8.3$ \\
\hline Duration of current abstinence (days) & $5.6^{*}$ & - & $2.1 \pm 2.9$ & $31.6 \pm 25.1$ \\
\hline Cocaine use during last $30 \mathrm{~d}$ : days/week & $5.7^{*}$ & - & $3.7 \pm 2.6$ & $1.4 \pm 2.0$ \\
\hline Cocaine use during last $30 \mathrm{~d}$ : $\$ /$ sitting & 0.2 & - & $98.7 \pm 91.4$ & $100.0 \pm 165.8$ \\
\hline Cocaine use during last 12 months: days/week & 1.1 & - & $4.4 \pm 2.5$ & $5.2 \pm 2.2$ \\
\hline Cocaine use during last 12 months: $\$$ /sitting & 0.7 & - & $102.5 \pm 100.4$ & $136.4 \pm 148.5$ \\
\hline Maximum cocaine use (days/week) & 0.4 & - & $6.0 \pm 1.8$ & $6.0 \pm 1.7$ \\
\hline Total score on the Cocaine Selective Severity Assessment Scale & $2.9^{*}$ & - & $20.0 \pm 10.7$ & $12.8 \pm 7.6$ \\
\hline Severity of Dependence Scale (0-15) & 1.8 & - & $8.0 \pm 3.4$ & $9.8 \pm 2.4$ \\
\hline Cocaine Craving Questionnaire $(0-45)$ & $4.2^{*}$ & - & $24.12 \pm 10.5$ & $12.8 \pm 10.1$ \\
\hline
\end{tabular}

the major termini of mesencephalic dopaminergic projections (Nieuwenhuis et al., 2004a; Carlson et al., 2011). FN is reported to be sensitive to phasic corticostriatal dopaminergic activity (Hauser et al., 2014) and tracks bidirectional ( \pm )RPE signaling (Holroyd et al., 2003; Pfabigan et al., 2011). Previous studies in addiction have investigated $\mathrm{FN}$ as a marker of sensitivity to reward expectation (Franken et al., 2010; Euser et al., 2011; Muñoz et al., 2012) or of outcome evaluation (Fein and Chang, 2008; Euser et al., 2013), but importantly never as a marker of RPE.

Here, we reasoned that a targeted task could leverage FN to index RPE in addiction. Therefore, we evoked FN using a gambling task and hypothesized that cocaine-use disorder (CUD) will manifest deficits in computing both positive RPE (+RPE) and negative RPE ( $-\mathrm{RPE})$. Given previous reports of more severe executive function (Woicik et al., 2009) and reward processing impairments (Parvaz et al., 2012) in addicted individuals with less-recent drug use (i.e., CUD individuals with longer current abstinence length and less-frequent current drug use), we further hypothesized that less-recent cocaine use will be associated with more-severe RPE deficits.

\section{Materials and Methods}

Participants. Fifty CUD individuals ( 46 male) and 25 healthy controls (23 male) were recruited through advertisements in local newspapers, word of mouth, and local treatment facilities. All participants underwent full physical and neurological examinations by a neurologist and a diagnostic interview by a clinical psychologist. The diagnostic interview included the Structured Clinical Interview for Diagnostic and Statistical Manual of Mental Disorders, Fourth Edition, Axis I Disorders (First et al., 1996); the Addiction Severity Index (McLellan et al., 1992); the Cocaine Selective Severity Assessment Scale (Kampman et al., 1998); the Cocaine Craving Questionnaire (Tiffany et al., 1993); and the Severity of Dependence Scale (Gossop et al., 1992). Based on this interview, all CUD individuals were classified as meeting diagnostic criteria for current cocaine dependence.

Participants were further screened to exclude for the following: (1) history of head trauma or loss of consciousness ( $>30 \mathrm{~min}$ ) or any other neurological disease; (2) abnormal vital signs at time of screening and history of major medical conditions; (3) history of major psychiatric disorders, including current dependence or abuse of any substance (other than cocaine abuse or dependence for CUD and/or nicotine dependence for all participants); (4) severe levels of self-reported depression (Beck Depression Inventory; Beck et al., 1996; scores, >20); (5) history of gambling as measured with the South Oaks Gambling Scale (Lesieur and Blume, 1987; scores, $\geq 5$ ); (6) except for cocaine in the CUD participants, positive urine screens for any other psychoactive drugs; and (7) current use of any medication, including psychotropic medications.

Similar to our previous studies (Moeller et al., 2010, 2013; Dunning et al., 2011; Parvaz et al., 2012), recent use of cocaine was objectively indexed by urine screening on study day using the triage urine panel (Biopsych), which detects drug use within the past $72 \mathrm{~h}$. Individuals positive for cocaine in urine, though not currently intoxicated, were classified as CUD $+(N=25)$, while those negative for cocaine in urine were classified as CUD- $(N=25)$. All CUD individuals used crack/cocaine in the previous $90 \mathrm{~d}$. As anticipated, the two CUD subgroups differed on frequency of recent cocaine use (days per week in past $30 \mathrm{~d}, p<0.001$ ), duration of current abstinence ( $p<0.001)$, self-reported craving $(p<$ $0.001)$, and withdrawal from cocaine $(p=0.006$; Table 1$)$. With the exception of cigarette smoking, the combined group of CUD individuals and controls did not differ on any demographic characteristics (Table 1). Only 5 (of 25) controls were current smokers compared with the majority (32 of 50) of CUD individuals, and this represented a significant difference $(p=0.001)$. However, daily cigarette use among the current smokers did not differ between the groups. Cigarette smokers were not required to abstain from smoking to avoid acute nicotine withdrawal effects. Participants were fully informed of all study procedures and risks and provided written consent in accordance with the Stony Brook University's Institutional Review Board.

Task. The overall design of the task is similar to Experiment 2 reported in a previous study by Hajcak et al. (2007). The task was administered using Presentation software (Neurobehavioral Systems) to control the presentation and timing of all stimuli. Participants' primary objective on each trial was to guess which of four doors presented horizontally in a color graphic hid a prize by pressing one of four keys on a keypad corresponding to each door (Fig. $1 A$ ). At the beginning of each trial, a white " 1 ," " 2 ," or " 3 " appeared on the screen for $1000 \mathrm{~ms}$ to inform participants the number of doors (out of four) that contained a monetary prize (60\$); 
A

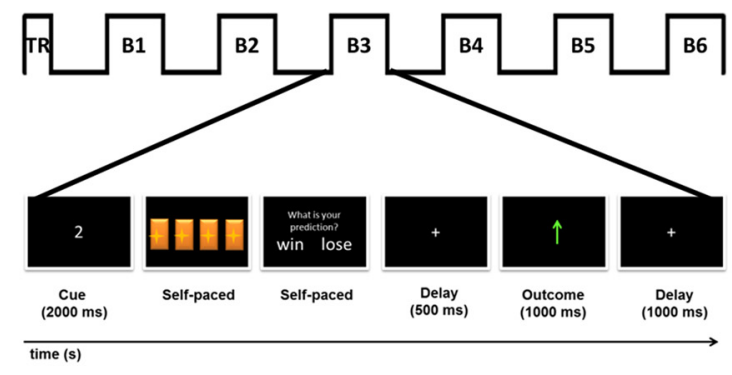

3 Cue Types; 100 trials per Cue Type; 300 trials total. 1 Training Session (TR); 6 Task Blocks (B1 through B6) 50 trials per Block
B

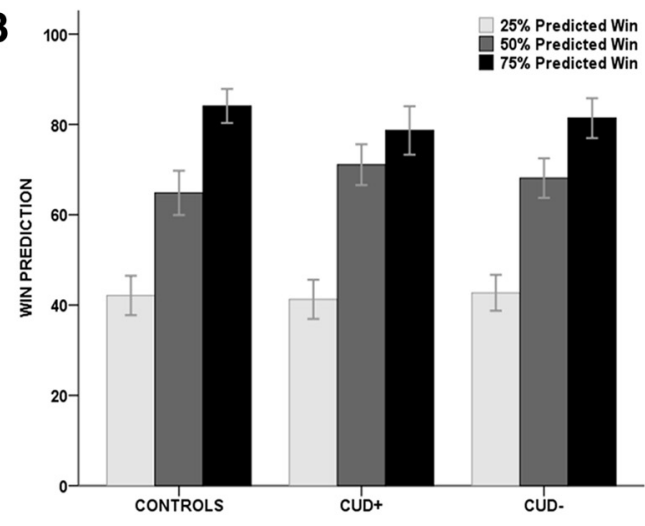

Figure 1. A, Sequence of events during a win trial of the gambling task. Based on a cue, the participants select a door and then identify if they expect to win or lose in that trial. A feedback of their accuracy was provided at the end of each trial. $\boldsymbol{B}$, Graph showing the proportion of win prediction for each cue type separately for each group. The pattern provides a behavioral validation of the effectiveness of task manipulations the study groups. The error bars show the standard error of mean (SEM).

thus, these cues indicated the probability of reward on the upcoming trial $(25,50$, and $75 \%$, respectively). The graphic of the doors appeared 1500 $\mathrm{ms}$ after cue offset, and remained until the participant made a selection to indicate their prediction of the winning door. Immediately following their choice, the question "Do you think you won or lost in this trial?" appeared on the screen and remained there until participants indicated via button press a predicted win or loss. Thus, participants were first presented with a cue that conveyed the objective probability of reward on the upcoming trial, then asked to make a choice and, finally, predicted whether or not they thought they chose correctly. Five hundred milliseconds following their prediction, a feedback stimulus appeared on the screen for $1000 \mathrm{~ms}$ : a green arrow pointing upward indicated a win (i.e., a win of $60 \$$ ), and a red arrow pointing downward indicated a loss (i.e., a loss of 30\$; Fig. 1A). Winning probability was always consistent with the cue type (e.g., 75\% winning probability for three-cue trials). Participants' prediction on each trial was recorded and subsequently analyzed to validate the success of the task manipulations in biasing reward prediction. Such a task design specifically allows for modulating valence-related variability in FN by explicit prediction errors (Hajcak et al., 2007).

All stimuli were positioned in the center of the screen. The cue and feedback stimuli occupied $\sim 21^{\circ}$ of visual angle horizontally and $21^{\circ}$ vertically. A fixation cross was then presented in the intertrial interval for $1000 \mathrm{~ms}$. The task consisted of six blocks of 50 pseudorandom trials (i.e., a total of 300 trials; 100 trials per cue type) interspaced by a brief break. Participants were told that the task earnings would be given to them at the end of the EEG session. Unbeknownst to the participants, the task earnings were not dependent on their choice and they were always paid $\$ 75$ for the task.

Electroencephalogram recording and data reduction. Electroencephalogram (EEG; Neuroscan) recordings were obtained using a 64 silver-silver chloride electrode cap positioned according to the International 10/20 system. Electro-oculogram electrodes at the left supraorbital and infraorbital sites and the right and left outer canthi recorded the blinks (and vertical eye movements) and horizontal eye movements, respectively. EEG recordings were sampled at $500 \mathrm{~Hz}$ and bandpass filtered from DC to $70 \mathrm{~Hz}$. Electrode impedances were kept $<10 \mathrm{k} \Omega$.

Offline preprocessing of the EEG signal was performed using SPM8 (Wellcome Department of Cognitive Neurology, London, UK; http://www.fil.ion.ucl.ac.uk/spm) and custom Matlab (The MathWorks) scripts. Data were first bandpass filtered $(0.01-30 \mathrm{~Hz})$ and rereferenced to the averaged electrical activity from all 64 scalp sites. To evaluate the effect of participant's actual predictions on the feedbacklocked ERP and to maximize the number of trials for each analysis, across the objective winning probabilities $(25,50$, and $75 \%)$, averaged waveforms were created for all four feedback trial types (i.e., predicted win, unpredicted win, predicted loss, and unpredicted loss). Therefore, the continuous EEG data were segmented beginning $200 \mathrm{~ms}$ before the feedback onset and continuing for $1000 \mathrm{~ms}$. For each trial, the $200 \mathrm{~ms}$ baseline was subtracted from the poststimulus data for baseline correction. Eyeblink and ocular corrections were performed using the partial signal space projection method proposed by Nolte and Hämäläinen (2001), such that the contribution to the estimated spatial structure of eye-blink artifact was removed only from the artifact-ridden epochs, leaving as much information as possible in the data (Nolte and Hämäläinen, 2001). This artifact-rejection procedure identified a voltage step of $>75 \mu \mathrm{V}$ between sample points and a peak-to-peak voltage difference of $150 \mu \mathrm{V}$ within an epoch. Additional artifacts were identified through visual inspection, and the contaminated epochs were subsequently rejected. Finally, robust averaging was used to create artifact-free ERPs (Wager et al., 2005) separately for each of the four conditions.

Based on the scalp topography of the grand-averaged difference waveforms (loss minus win for predicted and unpredicted conditions; Hajcak et al., 2007), the FN was defined as the averaged maximum negative amplitude at the Fz, FC1, FCz, and FC2 electrode sites from 200 to $350 \mathrm{~ms}$ following feedback onset. FN was scored in two different ways: (1) based on subjective prediction and outcome (i.e., predicted win, unpredicted win, predicted loss, and unpredicted loss); and (2) based on objective win probability and outcome (i.e., $25 \%$ win, $25 \%$ loss, $50 \%$ win, $50 \%$ loss, $75 \%$ win, and $75 \%$ loss). We expected the former, but not the latter, to specifically target RPE as there might be incongruencies in objective win probability and the participants' own expectation of reward. Additionally, to show that RPE uniquely modulates FN, P300 was also isolated for each outcome based on winning probability and prediction type at sites where P300 was maximal (i.e., F1, Fz, F2, FCz sites). The P300 was defined as the most positive peak in the $400-600 \mathrm{~ms}$ window following feedback onset.

Using SPSS (version 20), task behavior (subjective win/loss prediction) was analyzed with a 3 [Winning probability $(25,50$, and $75 \%)] \times 2$ [Predicted outcome (wins and losses)] $\times 3$ [Group (Controls, CUD+, and CUD-)] mixed-model ANOVA. In contrast, FN and P300 amplitudes were each analyzed with (1) 2 [Prediction (predicted and unpredicted)] $\times 2$ [Outcome (wins and losses)] $\times 3$ [Group (Controls, CUD +, and CUD-)] mixed-model ANOVA, to specifically assess the RPE signaling; and (2) 3 [Winning probability $(25,50$, and $75 \%)] \times 2$ [Outcome (wins and losses)] $\times 3$ [Group (Controls, CUD+, and CUD-)] mixed-model ANOVA, to assess the specificity of objective win probability to target RPE. In instances where the sphericity assumption was violated, the Greenhouse-Geisser correction was applied. All significant main effects and interactions were followed with pairwise $t$ tests.

Finally, due to our a priori hypothesis regarding more severe impairments as a function of longer current abstinence length and lessfrequent current drug use, correlations between the dependent measures (ERPs and behavior) and variables indexing recent druguse history and related symptoms (listed in Table 1) were examined within each CUD subgroup. 
Table 2. FN amplitudes as a function of condition for all study groups ${ }^{a}$

\begin{tabular}{llllll}
\hline & \multicolumn{2}{l}{ Predicted $(\mu \mathrm{V})$} & & \multicolumn{2}{l}{ Unpredicted $(\mu \mathrm{V})$} \\
\cline { 2 - 3 } & Win & Loss & & Win & Loss \\
\hline Controls & $5.57 \pm 3.50$ & $4.02 \pm 2.90$ & & $6.49 \pm 3.58$ & $3.44 \pm 2.85$ \\
CUD + & $5.50 \pm 2.77$ & $4.38 \pm 2.10$ & & $6.32 \pm 3.29$ & $3.98 \pm 2.80$ \\
CUD - & $5.67 \pm 2.21$ & $3.37 \pm 2.93$ & & $5.81 \pm 3.20$ & $3.81 \pm 2.27$ \\
\hline
\end{tabular}

${ }^{a}$ Mean \pm SD

\section{Results}

\section{Behavioral results}

The 3 (Winning probability: 25, 50, and 75\%) $\times 2$ (Predicted outcome: Win and Loss) $\times 3$ (Group: Controls, CUD+, and CUD-) mixed ANOVA revealed a significant main effect of predicted outcome (Win $>$ Loss: $\left.F_{(1,72)}=54.22, p<0.001\right)$ and a winning probability-by-predicted outcome interaction $\left(F_{(2,71)}=\right.$ $58.54, p<0.001)$, while all other main effects and interactions did not reach significance $(p>0.1)$. Follow-up paired $t$ tests showed that all participants predicted losing more often than winning for the $25 \%$ winning probability $\left(t_{(74)}=3.30, p=0.002\right)$ and predicted winning more often than losing for both the $50 \%\left(t_{(74)}=\right.$ 6.83, $p<0.001)$ and 75\% $\left(t_{(74)}=12.00, p<0.001\right)$ winning probabilities, confirming that the task manipulations were successful in biasing reward prediction (Fig. 1B).

\section{ERP results}

FN

The 2 (Prediction: Predicted and Unpredicted) $\times 2$ (Outcome: Win and Loss) $\times 3$ (Group: Controls, CUD+, and CUD-) mixed ANOVA for FN amplitude indicated a significant main effect for outcome (Win $>$ Loss: $F_{(1,72)}=102.4, p<0.001$ ), a significant prediction-by-outcome interaction $\left(F_{(1,72)}=10.64\right.$, $p=0.002)$, and a significant prediction-by-outcome-by-group interaction $\left(F_{(2,72)}=5.58, p=0.006\right)$. Follow-up comparisons revealed that, in controls only, FN amplitude was significantly higher for unpredicted versus predicted wins (Unpredicted Win $>$ Predicted Win: $t_{(24)}=3.12, p=0.005$ ) and significantly lower for unpredicted versus predicted losses (Unpredicted Loss $<$ Predicted Loss; $t_{(24)}=2.50, p=0.020$ ) as would be expected if the FN was tracking both +RPEs and - RPEs.

CUD + individuals also showed significantly higher FN amplitude for unpredicted versus predicted wins (Unpredicted Win $>$ Predicted Win; $t_{(24)}=2.38, p=0.026$ ) but no significant effects were observed for unpredicted versus predicted losses $(p=0.337)$. CUD - individuals did not show FN differences either between unpredicted and predicted wins $(p=0.719)$, or between unpredicted and predicted losses $(p=0.203)$. Thus, the current results show that, compared with healthy controls, both CUD subgroups manifest impairments in - RPE signaling as indexed by the lack of FN amplitude modulation to unpredicted versus predicted losses; CUD - individuals show additional impairments in +RPE signaling as indexed by the lack of FN amplitude modulation by unpredicted versus predicted wins (Table 2; Fig. 2A-D).

The exploratory 3 (Winning probability: 25, 50, and 75\%) $\times 2$ (Outcome: Win and Loss) $\times 3$ (Group: Controls, CUD+, and CUD-) mixed ANOVA revealed a significant main effect of outcome (Win $>$ Loss: $F_{(1,72)}=69.72, p<0.001$ ) and a winning probability-by-outcome interaction $\left(F_{(2,71)}=7.24, p=0.001\right)$, while all other main effects and interactions did not reach significance $(p>0.1)$. Follow-up paired $t$ tests showed that the loss minus win differential FN amplitude was significantly higher for the $50 \%$ condition compared with the amplitude for the $75 \%$ condition across all participants $\left(t_{(74)}=3.82, p<0.001\right)$.

\section{P300}

The 2 (Prediction: Predicted and Unpredicted) $\times 2$ (Outcome: Win and Loss) $\times 3$ (Group: Controls, CUD + , and CUD-) mixed ANOVA for P300 amplitude indicated a significant main effect for prediction (Unpredicted $>$ Predicted: $F_{(1,72)}=15.42, p$ $<0.001)$. All other main effects and other interactions did not reach significance.

The 3 (Winning probability: 25, 50, and 75\%) $\times 2$ (Outcome: Win and Loss) $\times 3$ (Group: Controls, CUD+, and CUD-) mixed ANOVA revealed a significant winning probability-byoutcome interaction $\left(F_{(2,71)}=17.6, p<0.001\right)$, while all other main effects and interactions did not reach significance $(p>0.1)$. Follow-up paired $t$ tests showed higher P300 amplitude to win compared with loss for the $25 \%$ winning probability $\left(t_{(74)}=3.30\right.$, $p=0.002)$, no difference for the $50 \%$ condition $(p=0.65)$, and higher P300 amplitude to loss compared with win for the 75\% winning probability across all participants $\left(t_{(74)}=4.79, p<\right.$ $0.001)$.

\section{Examination of potential confounds}

History of cigarette smoking significantly differed between the groups such that most CUD individuals (32 of 50) were current smokers, whereas only 5 of 25 healthy controls were current smokers. Therefore, a subanalysis was performed only in currently nonsmoking participants $(20$ controls and 18 CUD individuals). In this analysis CUD+ and CUD - individuals were assessed together as a CUD group due to statistical power constraints. For analyses based on subjective prediction, the results were consistent with findings in the entire sample such that there was a significant main effect for outcome (Win $>$ Loss: $F_{(1,36)}=$ $42.05, p<0.001)$ and a significant prediction-by-outcome interaction $\left(F_{(1,36)}=7.81, p=0.008\right)$. The three-way prediction-byoutcome-by-group interaction $\left(F_{(1,36)}=2.74, p=0.11\right)$ showed a trend in the same direction as in the larger sample, but did not reach significance, likely due to reduced power and fewer degrees of freedom (i.e., the group factor was reduced from three levels to two). Similarly, for analyses based on the objective win probability, the $3 \times 2 \times 2$ mixed ANOVA revealed a significant main effect of outcome (Win $>$ Loss: $\left.F_{(1,36)}=22.16, p<0.001\right)$ and a winning probability-by-outcome interaction $\left(F_{(1,36)}=3.70, p=\right.$ $0.038)$, while all other main effects and interactions did not reach significance $(p>0.1)$.

\section{Discussion}

The current study examined +RPE and - RPE signaling as indexed by the modulation of the FN component of the ERPs by predicted and unpredicted wins and losses and the component's putative impairment in drug addiction. Our results showed increased FN amplitude in response to unpredicted reward relative to predicted reward and decreased FN amplitude in response to unpredicted loss relative to predicted loss in healthy controls, which is consistent with the proposed biphasic corticostriatal dopaminergic activity underlying RPEs (Liu et al., 2007; Maia and Frank, 2011). Indeed, these results corroborate previous findings of FN modulation by unpredicted wins or losses compared with predicted wins or losses (Hajcak et al., 2007; Oliveira et al., 2007; Holroyd et al., 2008) and strengthen the developing literature that highlights sensitivity of the FN amplitude to the bidirectional RPE computation in health (Wu and Zhou, 2009; Pfabigan et al., 2011; also see, Talmi et al., 2013). 
A

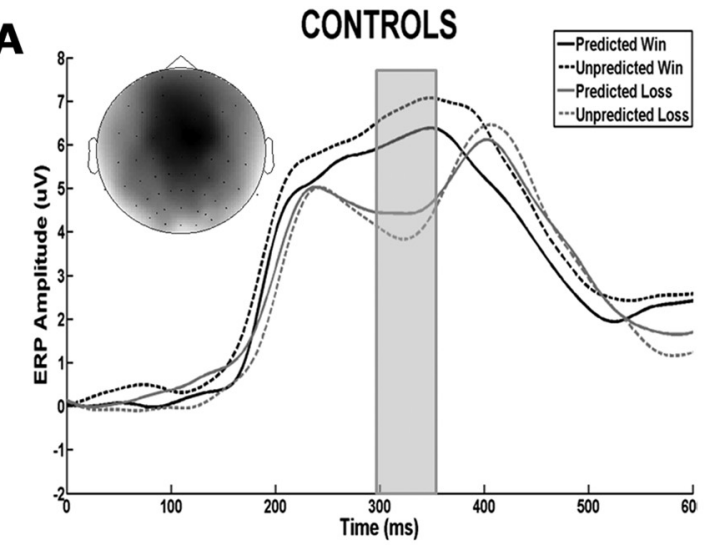

C

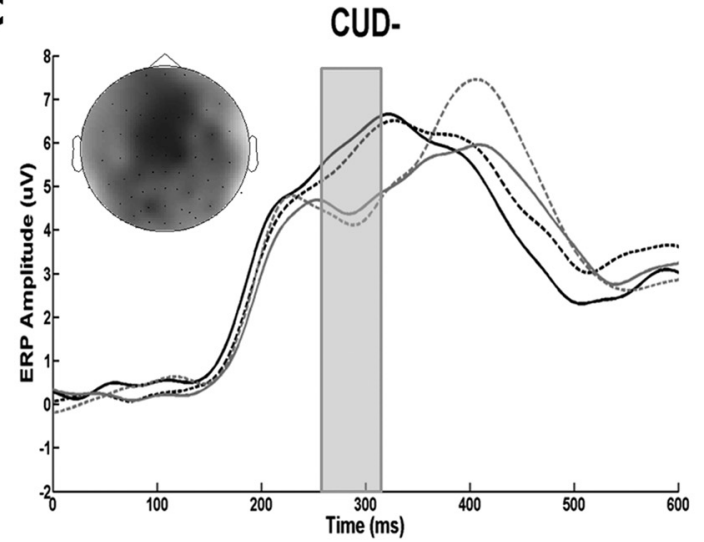

B

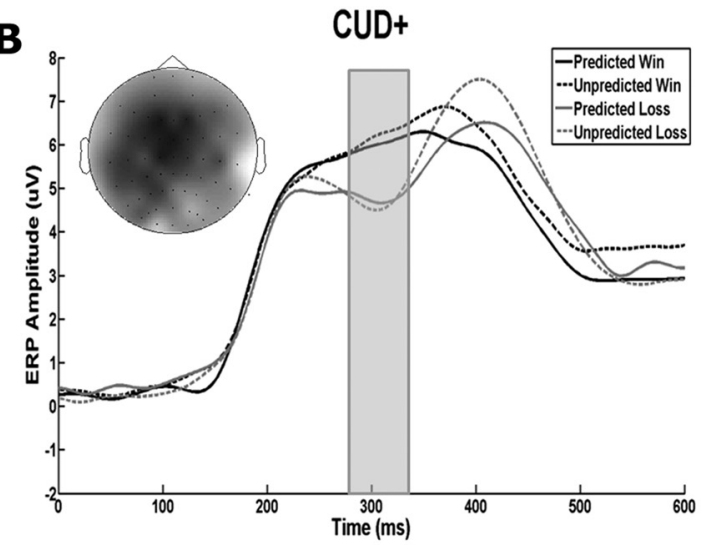

D

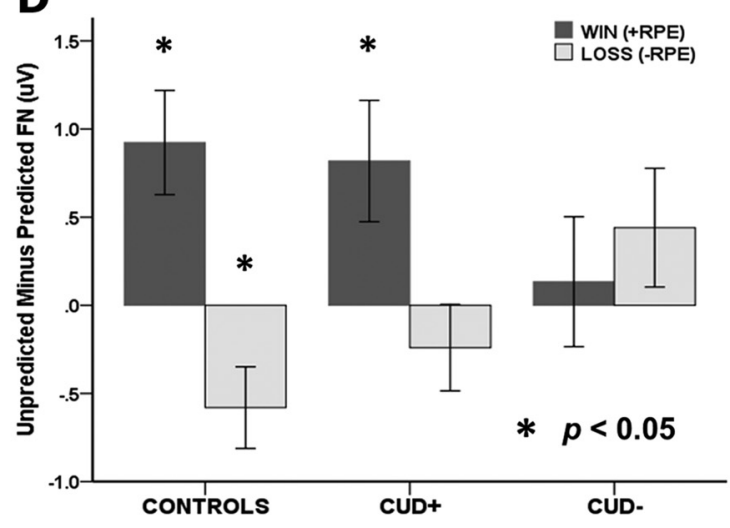

Figure 2. $\boldsymbol{A}-\boldsymbol{C}$, Grand averaged ERP waveforms at the FCz electrode for Predicted Win, Unpredicted Win, Predicted Loss, and Unpredicted Loss conditions separately for (A) Controls, (B) CUD +, and (C) CUD - . The highlighted window represents the temporal region of interest from where FN amplitude was scored. $A-C$ also show P300 amplitude ( $\sim 400 \mathrm{~ms})$ that is higher for unpredicted relative to predicted outcomes. $\boldsymbol{D}$, Bar graphs with electrocortical markers of $+\mathrm{RPE}$ (unpredicted minus predicted reward) and - RPE (unpredicted minus predicted loss) signaling showing intact RPE signaling in healthy controls and impaired signaling in CUD individuals. Asterisk designates significant differences $(p<0.05)$ between unpredicted and predicted outcomes.

The novel results of the current study show impaired RPE signaling in CUD individuals. Specifically, the current results show that FN amplitude in CUD individuals with less-frequent current cocaine use and longer abstinence (i.e., CUD-) did not differ in response to predicted and unpredicted outcomes (i.e., wins and losses), indicative of an overall deficit in RPE computation. Those individuals with more-frequent recent cocaine use and shorter abstinence (i.e., CUD+) showed intact + RPE computation similar to that of healthy controls and impaired - RPE similar to that of CUD - individuals. The results in CUD - individuals are consistent with those of a recent fMRI study that reported attenuated medial orbitofrontal cortex response to a computationally modeled absolute RPE measure in abstinent polysubstance users compared with controls (Tanabe et al., 2013).

The + RPE deficits in CUD - individuals perhaps point to an underlying reduction of tonic dopaminergic transmission in the striatum and reduced dopamine receptor availability resulting in reduced excitability of the reward system, as indicated by an increase in the threshold for brain stimulation for reward (Melis et al., 2005). Acute cocaine administration (as in CUD+ individuals) yields an enhanced dopamine surge, which lowers the threshold for exciting the reward system (Koob et al., 1998) and therefore may also normalize + RPE signaling in the addicted individuals with the most-frequent and most-recent cocaine use. Therefore, the current +RPE results in CUD individuals are consistent with the self-medication hypothesis of addiction (Khantzian, 1997). The temporary suppression of processing deficits by acute cocaine use is not surprising given similar prior results when acutely administering cocaine (Garavan et al., 2008) or methylphenidate (a dopamine partial agonist; Goldstein et al., 2010) to cocaine-addicted individuals. These results also extend our previous findings of more-severe deficits in executive functioning (Woicik et al., 2009) and reward-magnitude sensitivity (Parvaz et al., 2012) in CUD - individuals compared with CUD+ individuals. Note that these results cannot be attributed to more withdrawal in the CUD - individuals as craving and withdrawal were higher in CUD+ individuals.

Most interestingly, the current results highlight deficits in - RPE across all CUD individuals; that is, regardless of the frequency and recency of current cocaine use, there was no impact of prediction on the neural response to loss in CUD individuals. Although novel, these results are not surprising given previous neurochemical reports of sluggish activity in dopaminergic neurons (Volkow et al., 1997; Martinez et al., 2009), further contributing to individual vulnerability to relapse (Hyman et al., 2006; Schultz, 2011). This vulnerability may become more severe with longer abstinence (Tran-Nguyen et al., 1998; Ciccocioppo et al., 2001). Indeed, an impaired response to unpredicted loss in CUD individuals is consistent with findings in other disorders of inhibitory control, such as gambling, where, compared with healthy controls, pathological gamblers show reduced frontostriatal activity on a modified monetary incentive delay task specifically to a loss versus a neutral condition (Balodis et al., 2012).

Alternatively, dysregulation in the serotonin system may also underlie - RPE deficits in CUD individuals. It has previously 
been suggested that dopamine codes positive and negative prediction errors in tandem with a second opponent system specialized for the negative component of the prediction error, the dorsal raphe serotonin system (Daw et al., 2002). Acute tryptophan depletion, which reduces the availability of central serotonin (5-HT), selectively potentiates punishment prediction (i.e., leaving reward prediction intact; Cools et al., 2008). Interestingly, cocaine-dependent individuals exhibit reduced 5-HT1B receptor availability in several cortical and subcortical regions relative to controls (Matuskey et al., 2014), which may possibly reflect increased endogenous 5-HT levels or 5-HT1B receptor downregulation. Thus, impaired - RPE in CUD individuals may also reflect a primary dysfunction in the serotonin system, or in its interaction with the dopamine system. Lateral habenula ( $\mathrm{LHb})$ is one such extrastriatal region that is posited to influence both serotonin (Stern et al., 1981) and striatal dopamine, specifically in dynamic trial-by-trial aversive learning in humans (Lawson et al., 2014) and in nonhuman primates (Matsumoto and Hikosaka, 2007). Thus, the current results of - RPE deficits in CUD individuals are also consistent with recently implicated dysfunctional LHb activity in drug addiction (Velasquez et al., 2014).

Together, the - RPE deficits in both CUD subgroups may reflect an underlying impairment in dopaminergic regulation of learning from disadvantageous experiences, regardless of the recent drug-use pattern. Additionally, this dysregulated dopamine activity may contribute to problems in executive function, such as impaired cognitive control/flexibility (Schoenbaum et al., 2004; Ersche et al., 2008; Liu et al., 2008) and working memory (Tomasi et al., 2007; George et al., 2008; Porter et al., 2011) that are frequently reported in drug addiction. Unlike + RPE signaling, which was intact in CUD+ individuals, deficits in - RPE in all CUD individuals could highlight predisposing factors that may enhance an individual's proclivity toward drug addiction. Alternatively, impaired - RPE could also be a consequence of chronic drug use, but one that is not affected by recent drug use. Future studies could probe the fidelity of - RPE signaling in young adults and at-risk populations to explore whether there are RPE-related deficits that exist before the initiation of drug use or the transition to drug addiction. If this hypothesis is ultimately supported, - RPE could potentially serve as a biomarker for the propensity to develop addiction.

A potential limitation of the current study is that the 25 and $75 \%$ winning probability conditions greatly biased the prediction toward predicted loss and predicted win, respectively, and yielded very few unpredicted loss trials for the $25 \%$ condition and unpredicted win trials for the $75 \%$ condition. Future studies may use other winning probabilities (such as $0,30,60,90$, and $100 \%$ ) to allow increased variation per condition so that RPEs could be evaluated separately for each probability. Second, the task requirement of making a dichotomous prediction on each trial may have changed the meaning of the feedback. For example, when participants correctly predicted a loss, the subsequent negative feedback could simultaneously indicate a correct prediction as well as a loss. However, previous studies have shown that while FN tracks the monetary value of the feedback, it is insensitive to its performance-related aspect (Nieuwenhuis et al., 2004b; Hajcak et al., 2007). Nevertheless, these are the first results using electrocortical biomarkers to elucidate RPE-related disruption in CUD individuals and its association with current drug use. This is important because the increased temporal resolution of neuronal activity afforded by EEG compared with fMRI may be particularly well suited to capture phasic neural processes, such as RPE.
In sum, the current results show absence of a modulation of a direct electrocortical measure of RPE (i.e., the FN) by the prediction of loss in CUD individuals. Similar deficits in both active and abstinent users may be indicative of an underlying trait-like vulnerability to addiction, although this speculation needs to be verified in future longitudinal studies. These results are consequential, as they reflect the neurophysiology underlying persistent disadvantageous behaviors in addicted individuals, such as frequent imprisonment, loss of family and friends, and relapse to drug use, which may reflect the inability of these individuals to learn from unfavorable outcomes. Although most reward processing-related studies investigate the underlying mechanisms of positive prediction error in addiction, the current results highlight the importance of investigating mechanisms underlying the processing of negative prediction error. Moreover, FN modulation by positive reward prediction differed as a function of recency of cocaine use such that it was intact in active users but impaired in cocaineaddicted individuals with recent abstinence. These deficits may thus contribute to relapse risk; that is, to the extent that cocaine may temporarily normalize underlying cognitive, behavioral, and emotional disruptions, abstinent users may revert back to drug use to normalize these impairments.

\section{References}

Balodis IM, Kober H, Worhunsky PD, Stevens MC, Pearlson GD, Potenza MN (2012) Diminished frontostriatal activity during processing of monetary rewards and losses in pathological gambling. Biol Psychiatry 71:749-757. CrossRef Medline

Beck AT, Steer RA, Ball R, Ranieri W (1996) Comparison of Beck Depression Inventories-IA and -II in psychiatric outpatients. J Pers Assess 67: 588-597. CrossRef Medline

Carlson JM, Foti D, Mujica-Parodi LR, Harmon-Jones E, Hajcak G (2011) Ventral striatal and medial prefrontal BOLD activation is correlated with reward-related electrocortical activity: a combined ERP and fMRI study. Neuroimage 57:1608-1616. CrossRef Medline

Chiu PH, Lohrenz TM, Montague PR (2008) Smokers' brains compute, but ignore, a fictive error signal in a sequential investment task. Nat Neurosci 11:514-520. CrossRef Medline

Ciccocioppo R, Sanna PP, Weiss F (2001) Cocaine-predictive stimulus induces drug-seeking behavior and neural activation in limbic brain regions after multiple months of abstinence: reversal by $\mathrm{D}(1)$ antagonists. Proc Natl Acad Sci U S A 98:1976-1981. CrossRef Medline

Cohen JY, Haesler S, Vong L, Lowell BB, Uchida N (2012) Neuron-typespecific signals for reward and punishment in the ventral tegmental area. Nature 482:85-88. CrossRef Medline

Cools R, Robinson OJ, Sahakian B (2008) Acute tryptophan depletion in healthy volunteers enhances punishment prediction but does not affect reward prediction. Neuropsychopharmacology 33:2291-2299. CrossRef Medline

Daw ND, Kakade S, Dayan P (2002) Opponent interactions between serotonin and dopamine. Neural Netw 15:603-616. CrossRef Medline

Di Chiara G (1998) A motivational learning hypothesis of the role of mesolimbic dopamine in compulsive drug use. J Psychopharmacol 12:54-67. CrossRef Medline

Dunning JP, Parvaz MA, Hajcak G, Maloney T, Alia-Klein N, Woicik PA, Telang F, Wang GJ, Volkow ND, Goldstein RZ (2011) Motivated attention to cocaine and emotional cues in abstinent and current cocaine users-an ERP study. Eur J Neurosci 33:1716-1723. CrossRef Medline

Ersche KD, Roiser JP, Robbins TW, Sahakian BJ (2008) Chronic cocaine but not chronic amphetamine use is associated with perseverative responding in humans. Psychopharmacology (Berl) 197:421-431. CrossRef Medline

Euser AS, van Meel CS, Snelleman M, Franken IH (2011) Acute effects of alcohol on feedback processing and outcome evaluation during risky decision-making: an ERP study. Psychopharmacology (Berl) 217:111125. CrossRef Medline

Euser AS, Greaves-Lord K, Crowley MJ, Evans BE, Huizink AC, Franken IH (2013) Blunted feedback processing during risky decision making in adolescents with a parental history of substance use disorders. Dev Psychopathol 25:1119-1136. CrossRef Medline 
Everitt BJ, Robbins TW (2005) Neural systems of reinforcement for drug addiction: from actions to habits to compulsion. Nat Neurosci 8:14811489. CrossRef Medline

Fein G, Chang M (2008) Smaller feedback ERN amplitudes during the BART are associated with a greater family history density of alcohol problems in treatment-naive alcoholics. Drug Alcohol Depend 92:141-148. CrossRef Medline

First MB, Gibbon M, Spitzer RL (1996) User's guide for the structured clinical interview for Axis I DSM-IV Disorders-Research Version. New York: Biometrics Research.

Frank MJ, Claus ED (2006) Anatomy of a decision: striato-orbitofrontal interactions in reinforcement learning, decision making, and reversal. Psychol Rev 113:300-326. CrossRef Medline

Franken IH, Van den Berg I, Van Strien JW (2010) Individual differences in alcohol drinking frequency are associated with electrophysiological responses to unexpected nonrewards. Alcohol Clin Exp Res 34:702-707. CrossRef Medline

Garavan H, Kaufman JN, Hester R (2008) Acute effects of cocaine on the neurobiology of cognitive control. Philos Trans R Soc Lond B Biol Sci 363:3267-3276. CrossRef Medline

George O, Mandyam CD, Wee S, Koob GF (2008) Extended access to cocaine self-administration produces long-lasting prefrontal cortexdependent working memory impairments. Neuropsychopharmacology 33:2474-2482. CrossRef Medline

Glimcher PW (2011) Understanding dopamine and reinforcement learning: the dopamine reward prediction error hypothesis. Proc Natl Acad Sci U S A 108 [Suppl 3]:15647-15654. CrossRef Medline

Goldstein RZ, Woicik PA, Maloney T, Tomasi D, Alia-Klein N, Shan J, Honorio J, Samaras D, Wang R, Telang F, Wang GJ, Volkow ND (2010) Oral methylphenidate normalizes cingulate activity in cocaine addiction during a salient cognitive task. Proc Natl Acad Sci U S A 107:16667-16672. CrossRef Medline

Gossop M, Griffiths P, Powis B, Strang J (1992) Severity of dependence and route of administration of heroin, cocaine and amphetamines. Br J Addict 87:1527-1536. CrossRef Medline

Gradin VB, Baldacchino A, Balfour D, Matthews K, Steele JD (2014) Abnormal brain activity during a reward and loss task in opiate-dependent patients receiving methadone maintenance therapy. Neuropsychopharmacology 39:885-894. CrossRef Medline

Hajcak G, Moser JS, Holroyd CB, Simons RF (2007) It's worse than you thought: the feedback negativity and violations of reward prediction in gambling tasks. Psychophysiology 44:905-912. CrossRef Medline

Hart AS, Rutledge RB, Glimcher PW, Phillips PE (2014) Phasic dopamine release in the rat nucleus accumbens symmetrically encodes a reward prediction error term. J Neurosci 34:698-704. CrossRef Medline

Hauser TU, Iannaccone R, Stämpfli P, Drechsler R, Brandeis D, Walitza S, Brem S (2014) The feedback-related negativity (FRN) revisited: new insights into the localization, meaning and network organization. Neuroimage 84:159-168. CrossRef Medline

Hollerman JR, Schultz W (1998) Dopamine neurons report an error in the temporal prediction of reward during learning. Nat Neurosci 1:304-309. CrossRef Medline

Holroyd CB, Nieuwenhuis S, Yeung N, Cohen JD (2003) Errors in reward prediction are reflected in the event-related brain potential. Neuroreport 14:2481-2484. CrossRef Medline

Holroyd CB, Pakzad-Vaezi KL, Krigolson OE (2008) The feedback correctrelated positivity: sensitivity of the event-related brain potential to unexpected positive feedback. Psychophysiology 45:688-697. CrossRef Medline

Hyman SE, Malenka RC, Nestler EJ (2006) Neural mechanisms of addiction: the role of reward-related learning and memory. Annu Rev Neurosci 29:565-598. CrossRef Medline

Jones SR, Garris PA, Wightman RM (1995) Different effects of cocaine and nomifensine on dopamine uptake in the caudate-putamen and nucleus accumbens. J Pharmacol Exp Ther 274:396-403. Medline

Kampman KM, Volpicelli JR, McGinnis DE, Alterman AI, Weinrieb RM, D'Angelo L, Epperson LE (1998) Reliability and validity of the Cocaine Selective Severity Assessment. Addict Behav 23:449-461. CrossRef Medline

Khantzian EJ (1997) The self-medication hypothesis of substance use disorders: a reconsideration and recent applications. Harv Rev Psychiatry 4:231-244. CrossRef Medline
Koob GF, Le Moal M (2001) Drug addiction, dysregulation of reward, and allostasis. Neuropsychopharmacology 24:97-129. CrossRef Medline

Koob GF, Sanna PP, Bloom FE (1998) Neuroscience of addiction. Neuron 21:467-476. CrossRef Medline

Lawson RP, Seymour B, Loh E, Lutti A, Dolan RJ, Dayan P, Weiskopf N, Roiser JP (2014) The habenula encodes negative motivational value associated with primary punishment in humans. Proc Natl Acad Sci U S A 111:11858-11863. CrossRef Medline

Lesieur HR, Blume SB (1987) The South Oaks Gambling Screen (SOGS): a new instrument for the identification of pathological gamblers. Am J Psychiatry 144:1184-1188. Medline

Liu S, Heitz RP, Sampson AR, Zhang W, Bradberry CW (2008) Evidence of temporal cortical dysfunction in rhesus monkeys following chronic cocaine self-administration. Cereb Cortex 18:2109-2116. CrossRef Medline

Liu X, Powell DK, Wang H, Gold BT, Corbly CR, Joseph JE (2007) Functional dissociation in frontal and striatal areas for processing of positive and negative reward information. J Neurosci 27:4587-4597. CrossRef Medline

Maia TV, Frank MJ (2011) From reinforcement learning models to psychiatric and neurological disorders. Nat Neurosci 14:154-162. CrossRef Medline

Martinez D, Greene K, Broft A, Kumar D, Liu F, Narendran R, Slifstein M, Van Heertum R, Kleber HD (2009) Lower level of endogenous dopamine in patients with cocaine dependence: findings from PET imaging of $\mathrm{D}(2) / \mathrm{D}(3)$ receptors following acute dopamine depletion. Am J Psychiatry 166:1170-1177. CrossRef Medline

Matsumoto M, Hikosaka O (2007) Lateral habenula as a source of negative reward signals in dopamine neurons. Nature 447:1111-1115. CrossRef Medline

Matuskey D, Bhagwagar Z, Planeta B, Pittman B, Gallezot JD, Chen J, Wanyiri J, Najafzadeh S, Ropchan J, Geha P, Huang Y, Potenza MN, Neumeister A, Carson RE, Malison RT (2014) Reductions in brain 5-HT receptor availability in primarily cocaine-dependent humans. Biol Psychiatry 76: 816-822. CrossRef Medline

McClure SM, Berns GS, Montague PR (2003) Temporal prediction errors in a passive learning task activate human striatum. Neuron 38:339-346. CrossRef Medline

McLellan AT, Kushner H, Metzger D, Peters R, Smith I, Grissom G, Pettinati H, Argeriou M (1992) The Fifth Edition of the Addiction Severity Index. J Subst Abuse Treat 9:199-213. CrossRef Medline

Melis M, Spiga S, Diana M (2005) The dopamine hypothesis of drug addiction: hypodopaminergic state. Int Rev Neurobiol 63:101-154. CrossRef Medline

Mirenowicz J, Schultz W (1994) Importance of unpredictability for reward responses in primate dopamine neurons. J Neurophysiol 72:1024-1027. Medline

Moeller SJ, Maloney T, Parvaz MA, Alia-Klein N, Woicik PA, Telang F, Wang GJ, Volkow ND, Goldstein RZ (2010) Impaired insight in cocaine addiction: laboratory evidence and effects on cocaine-seeking behaviour. Brain 133:1484-1493. CrossRef Medline

Moeller SJ, Parvaz MA, Shumay E, Beebe-Wang N, Konova AB, Alia-Klein N, Volkow ND, Goldstein RZ (2013) Gene $\times$ abstinence effects on drug cue reactivity in addiction: multimodal evidence. J Neurosci 33:1002710036. CrossRef Medline

Montague PR, Hyman SE, Cohen JD (2004) Computational roles for dopamine in behavioural control. Nature 431:760-767. CrossRef Medline

Muñoz MÁ, Anllo-Vento L, del Carmen Fernández M, Montoya P, Vila J (2012) Modulation of the outcome-related negativity associated with nicotine abstinence. Exp Clin Psychopharmacol 20:151-160. CrossRef Medline

Nieuwenhuis S, Holroyd CB, Mol N, Coles MG (2004a) Reinforcementrelated brain potentials from medial frontal cortex: origins and functional significance. Neurosci Biobehav Rev 28:441-448. CrossRef Medline

Nieuwenhuis S, Yeung N, Holroyd CB, Schurger A, Cohen JD (2004b) Sensitivity of electrophysiological activity from medial frontal cortex to utilitarian and performance feedback. Cereb Cortex 14:741-747. CrossRef Medline

Nolte G, Hämäläinen MS (2001) Partial signal space projection for artefact removal in MEG measurements: a theoretical analysis. Phys Med Biol 46:2873-2887. CrossRef Medline

Oliveira FT, McDonald JJ, Goodman D (2007) Performance monitoring in the anterior cingulate is not all error related: expectancy deviation and the 
representation of action-outcome associations. J Cogn Neurosci 19: 1994-2004. CrossRef Medline

Park SQ, Kahnt T, Beck A, Cohen MX, Dolan RJ, Wrase J, Heinz A (2010) Prefrontal cortex fails to learn from reward prediction errors in alcohol dependence. J Neurosci 30:7749-7753. CrossRef Medline

Parvaz MA, Maloney T, Moeller SJ, Woicik PA, Alia-Klein N, Telang F, Wang GJ, Squires NK, Volkow ND, Goldstein RZ (2012) Sensitivity to monetary reward is most severely compromised in recently abstaining cocaine addicted individuals: a cross-sectional ERP study. Psychiatry Res 203:75-82. CrossRef Medline

Pfabigan DM, Alexopoulos J, Bauer H, Sailer U (2011) Manipulation of feedback expectancy and valence induces negative and positive reward prediction error signals manifest in event-related brain potentials. Psychophysiology 48:656-664. CrossRef Medline

Porter JN, Olsen AS, Gurnsey K, Dugan BP, Jedema HP, Bradberry CW (2011) Chronic cocaine self-administration in rhesus monkeys: impact on associative learning, cognitive control, and working memory. J Neurosci 31:4926-4934. CrossRef Medline

Reynolds JN, Hyland BI, Wickens JR (2001) A cellular mechanism of reward-related learning. Nature 413:67-70. CrossRef Medline

Rice ME, Cragg SJ (2004) Nicotine amplifies reward-related dopamine signals in striatum. Nat Neurosci 7:583-584. CrossRef Medline

Rose EJ, Ross TJ, Salmeron BJ, Lee M, Shakleya DM, Huestis M, Stein EA (2012) Chronic exposure to nicotine is associated with reduced rewardrelated activity in the striatum but not the midbrain. Biol Psychiatry 71: 206-213. CrossRef Medline

Rose EJ, Salmeron BJ, Ross TJ, Waltz J, Schweitzer JB, McClure SM, Stein EA (2014) Temporal difference error prediction signal dysregulation in cocaine dependence. Neuropsychopharmacology 39:1732-1742. CrossRef Medline

Schoenbaum G, Saddoris MP, Ramus SJ, Shaham Y, Setlow B (2004) Cocaine-experienced rats exhibit learning deficits in a task sensitive to orbitofrontal cortex lesions. Eur J Neurosci 19:1997-2002. CrossRef Medline

Schultz W (1998) Predictive reward signal of dopamine neurons. J Neurophysiol 80:1-27. Medline

Schultz W (2011) Potential vulnerabilities of neuronal reward, risk, and decision mechanisms to addictive drugs. Neuron 69:603-617. CrossRef Medline

Schultz W, Romo R (1992) Role of primate basal ganglia and frontal cortex in the internal generation of movements. I. Preparatory activity in the anterior striatum. Exp Brain Res 91:363-384. Medline

Stern WC, Johnson A, Bronzino JD, Morgane PJ (1981) Neuropharmacology of the afferent projections from the lateral habenula and substantia nigra to the anterior raphe in the rat. Neuropharmacology 20:979-989. CrossRef Medline

Talmi D, Atkinson R, El-Deredy W (2013) The feedback-related negativity signals salience prediction errors, not reward prediction errors. J Neurosci 33:8264-8269. CrossRef Medline

Tanabe J, Reynolds J, Krmpotich T, Claus E, Thompson LL, Du YP, Banich MT (2013) Reduced neural tracking of prediction error in substancedependent individuals. Am J Psychiatry 170:1356-1363. CrossRef Medline

Tiffany ST, Singleton E, Haertzen CA, Henningfield JE (1993) The development of a cocaine craving questionnaire. Drug Alcohol Depend 34:19-28. CrossRef Medline

Tomasi D, Goldstein RZ, Telang F, Maloney T, Alia-Klein N, Caparelli EC, Volkow ND (2007) Widespread disruption in brain activation patterns to a working memory task during cocaine abstinence. Brain Res 1171:83-92. CrossRef Medline

Tran-Nguyen LT, Fuchs RA, Coffey GP, Baker DA, O’Dell LE, Neisewander JL (1998) Time-dependent changes in cocaine-seeking behavior and extracellular dopamine levels in the amygdala during cocaine withdrawal. Neuropsychopharmacology 19:48-59. CrossRef Medline

Velasquez KM, Molfese DL, Salas R (2014) The role of the habenula in drug addiction. Front Hum Neurosci 8:174. CrossRef Medline

Volkow ND, Wang GJ, Fowler JS, Logan J, Gatley SJ, Hitzemann R, Chen AD, Dewey SL, Pappas N (1997) Decreased striatal dopaminergic responsiveness in detoxified cocaine-dependent subjects. Nature 386:830-833. CrossRef Medline

Wager TD, Keller MC, Lacey SC, Jonides J (2005) Increased sensitivity in neuroimaging analyses using robust regression. Neuroimage 26:99-113. CrossRef Medline

Watanabe M (1996) Reward expectancy in primate prefrontal neurons. Nature 382:629-632. CrossRef Medline

Woicik PA, Moeller SJ, Alia-Klein N, Maloney T, Lukasik TM, Yeliosof O, Wang GJ, Volkow ND, Goldstein RZ (2009) The neuropsychology of cocaine addiction: recent cocaine use masks impairment. Neuropsychopharmacology 34:1112-1122. CrossRef Medline

Wu Y, Zhou X (2009) The P300 and reward valence, magnitude, and expectancy in outcome evaluation. Brain Res 1286:114-122. CrossRef Medline 